\title{
Balanço das Pesquisas sobre Formação/prática de Professores que ensinam Estatística, Probabilidade e Combinatória
}

\author{
An Overall Analysis of researches on training/practice of teachers \\ who teach Statistics, Probability and Combinatorics
}

Rodrigo Medeiros dos Santos ${ }^{1}$

\begin{abstract}
Resumo
O objetivo desta investigação foi desenvolver um balanço das teses e dissertações produzidas em programas brasileiros de pós-graduação até o ano de 2015, e que investigam a temática da formação/prática de professores que ensinam os conteúdos de Estatística, Probabilidade e Combinatória. Para tanto, as teses e dissertações foram coligidas em meio digital e posteriormente fichadas e catalogadas segundo as variáveis de interesse. Deste processo, emergiram 29 pesquisas, categorizadas em quatro subtemas: desenvolvimento profissional, formação inicial/continuada; prática docente; conhecimento profissional e saberes práticos; e Formação/Prática mediada por grupos colaborativos. Em cada uma dessas categorias a pesquisa foi descrita, destacando os principais focos de investigação, os aportes teóricos, abordagens metodológicas e principais resultados.
\end{abstract}

Palavras-chave: Formação de professores; Prática; Ensino de Estatística.

\begin{abstract}
The objective of this article was to develop an overall analysis of the theses and dissertations produced in Brazilian graduate programs up to the year 2015, and that investigate the theme training/practice of teachers who teach Statistics, Probability and Combinatorics. For that, the theses and dissertations were collected in digital environment and later cataloged according to the variables of interest. From this process, 29 researches emerged, categorized into four sub-themes: professional development, initial/continuing training; Teaching practice; Professional knowledge and practical knowledge; and Training/Practice mediated by collaborative groups. In each of these categories, the research was described, highlighting the main research foci, theoretical support, methodological approaches and main results.
\end{abstract}

Keywords: Teachers' training, practice, Statistics teaching.

\section{Ideias Iniciais}

Esta investigação desenvolve, em caráter de síntese, um balanço das pesquisas materializadas em teses e dissertações produzidas em programas brasileiros de pós-graduação até o ano de 2015, e que investigam a temática da formação/prática de professores que ensinam os conteúdos de Estatística, Probabilidade e Combinatória. O corpus de análise é composto por pesquisas que abordam problemas e questões relativas às temáticas que envolvem o desenvolvimento profissional, formação inicial/continuada, atuação/prática

\footnotetext{
${ }^{1}$ Doutor em Educação pela Universidade Estadual de Campinas (Unicamp). Professor da Universidade Federal do Oeste do Pará (UFOPA), Brasil. Email: rodrigomedeiros182@ hotmail.com
} 
docente, além do conhecimento profissional e saberes práticos mobilizados por professores atuantes nos diversos níveis de ensino.

A presente pesquisa deriva do estudo realizado por Santos (2015), que desenvolveu um estado da arte, coligindo teses e dissertações produzidas no campo da Educação Estatística em programas brasileiros de pós-graduação até o ano de 2012 (inclusive). Para o desenvolvimento da análise aqui levada a cabo, procedemos na atualização do catálogo de Santos (2015), com a inclusão de novas pesquisas produzidas no tema em questão até o ano de 2015 .

Do levantamento desenvolvido, despontaram 29 pesquisas - 11 teses de doutorado, 13 dissertações de mestrado acadêmico e cinco dissertações de mestrado profissional -, produzidas em 13 Universidades brasileiras ${ }^{2}$, sobretudo em programas de Educação, Educação Matemática e afins, no período que vai de 2002 a 2015, inclusive. Estas 29 pesquisas, cuja relação é apresentada no Apêndice 1 deste trabalho, são aqui alvo de nossa análise e, a partir delas, pretendemos realizar um breve balanço dessa produção, apontando e descrevendo os principais focos de análise, as ênfases, os principais aportes teóricos, abordagens metodológicas e alguns resultados.

\section{Procedimentos Metodológicos}

A presente pesquisa caracteriza-se metodologicamente como exploratória, quanto aos seus objetivos, e histórico-bibliográfica, segundo o seu processo de coleta e análise de dados.

As teses e dissertações que compõem o corpus de análise foram arroladas em meio digital. As fontes foram: o banco de teses e dissertações da Coordenação de Aperfeiçoamento de Pessoas de Nível Superior - CAPES; a Biblioteca Digital Brasileira de Teses e Dissertações - BDTD; e o acervo de currículos da plataforma Lattes.

Para a composição do corpus de análise não foi adotado um limite inferior para o intervalo de tempo em que as pesquisas foram defendidas, e o critério de seleção assumido foi: tomar teses e dissertações produzidas em programas brasileiros de pós-graduação produzidas até o ano de 2015 e que abordam problemas ou questões relacionadas à formação/prática de professores que ensinam os conteúdos de Estatística, Probabilidade e Combinatória nos diversos níveis de ensino ${ }^{3}$.

\footnotetext{
2 a saber: Pontifícia Universidade Católica de Campinas-PUC-Campinas (1); Pontifícia Universidade Católica de São Paulo - PUC-SP (9); Pontifícia Universidade Católica do Rio Grande do Sul-PUC-RS (1); Universidade Luterana do Brasil-ULBRA/Canoas (2); Universidade Anhanguera (1); Universidade Católica Dom Bosco (1); Universidade de Brasília (1); Universidade Estadual de Campinas-UNICAMP (5); Universidade Estadual Paulista-UNESP (1); Universidade Federal de Pernambuco-UFPE (3); Universidade Federal de Santa CatarinaUFSC (1); Universidade Federal do Paraná-UFPR (2); Universidade Federal do Rio de Janeiro-UFRJ (1).

${ }^{3} \mathrm{O}$ critério originalmente adotado em Santos (2015) foi: tomar teses e dissertações produzidas em programas de pós-graduação stricto sensu brasileiros até o ano de 2012 (inclusive), e que investigaram ou responderam indagações relativas a problemáticas do campo da Educação Estatística. Posteriormente, procedeu-se na Zetetiké, Campinas, SP, v.25, n1, jan./abr.2017, p.204-219

ISSN 2176-1744
} 
Cada pesquisa foi devidamente catalogada a partir da leitura do texto e da observação dos dados bibliográficos, e descrita segundo as variáveis de interesse, quais sejam: autor, ano de publicação, instituição, programa, conteúdo enfocado, problema e objetivos, metodologia, referenciais teóricos e principais contribuições/resultados apresentados.

Para a composição da análise, as pesquisas foram categorizadas em quatro subtemas: desenvolvimento profissional, formação inicial/continuada; prática docente; conhecimento profissional e saberes práticos; e Formação/Prática mediada por grupos colaborativos. As características da produção são apontadas e descritas em cada subtema e, posteriormente, são apontados, para o conjunto da produção, os principais aportes teóricos e abordagens metodológicas adotadas.

\section{Um Balanço da Produção}

Foram observadas, ao todo, 29 pesquisas, sendo nove no subtema Formação inicial/continuada e desenvolvimento profissional (Alves, 2012; Araújo, 2008; Canossa, 2009; Giusti, 2012; Herebia, 2002; Lemos, 2011; Pamplona, 2009; Rodrigues, 2011; Rodrigues, 2005); cinco no subtema Prática Docente (Carneiro, 2003; Alcântara, 2012; Gonçalves, 2005; Pereira, 2007; Silva, 2011); doze no subtema Conhecimento Profissional e Saberes Práticos (Bigattão Jr., 2007; Cardoso, 2007; Correa, 2011; Corrêa, 2010; Lopes, 2003; Oliveira, 2003; Rocha, 2011; Sabo, 2010; Santos, 2012; Junqueira, 2014; Bifi, 2014; Malara, 2008); e três no subtema Formação/Prática mediada por grupos colaborativos (Coelho, 2010; Conti, 2015; Veras, 2010).

O conteúdo de ensino mais enfocado pelas pesquisas foi o de Estatística (Araújo, 2008; Canossa, 2009; Herebia, 2002; Lemos, 2011; Pamplona, 2009; Alcântara, 2012; Carneiro, 2003; Gonçalves, 2005; Pereira, 2007; Silva, 2011; Cardoso, 2007; Bifi, 2014; Correa, 2011; Santos, 2012; Malara, 2008; Coelho, 2010; Conti, 2015; Veras, 2010). Todas as pesquisas categorizadas nos subtemas Prática docente e Formação/prática mediada por grupos colaborativos enfocaram o trabalho com o conteúdo de Estatística. O conteúdo de Probabilidade foi enfocado nos trabalhos de Rodrigues (2005), Rodrigues (2011), Corrêa (2010), Junqueira (2014) e Oliveira (2003). Já o trabalho com o conteúdo de Combinatória foi abordado nas pesquisas de Alves (2012), Rocha (2011) e Sabo (2010). As pesquisas de Lopes (2003), Bigattão Jr. (2007) e Giusti (2012) abordaram o trabalho com os conteúdos de Probabilidade e Estatística conjuntamente.

O Quadro 1 apresenta o conjunto das 29 pesquisas, descritas segundo o autor, ano de produção, nível da titulação obtida, instituição e foco ou objeto de estudo. Em seguida, são discutidos os objetivos e focos das pesquisas, os principais aportes teóricos e abordagens metodológicas utilizadas, além dos principais resultados e contribuições para o campo de pesquisa em cada um dos subtemas descritos.

categorização em eixos temáticos da pesquisa, onde o tema formação/prática de professores que ensinam os conteúdos de Estatística, Probabilidade e Combinatória compunha uma das categorias temáticas de estudo. 
DOI: http://dx.doi.org/10.20396/zet.v25il.8647576

Quadro 1: Teses e Dissertações produzidas no campo da Educação Estatística em programas brasileiros de pós-graduação, até 2012 inclusive, com a temática Formação/Atuação de professores que ensinam Estatística,

Probabilidade e Combinatória.

\begin{tabular}{|c|c|c|c|c|c|}
\hline $\mathrm{n}^{\mathrm{o}}$ & Autor & Ano & Nível & Instituição & Foco/Objeto de estudo \\
\hline \multicolumn{6}{|c|}{ Subtema: Formação Inicial/Continuada e Desenvolvimento Profissional } \\
\hline \multirow{9}{*}{9} & Alves & 2012 & MA & UFRJ & $\begin{array}{l}\text { Ideias apresentadas por futuros professores em formação } \\
\text { inicial sobre o ensino de Análise Combinatória }\end{array}$ \\
\hline & Araujo & 2008 & MA & UFSC & $\begin{array}{l}\text { Investigação da formação de professores pedagogos acerca da } \\
\text { problemática do ensino e aprendizagem de gráficos e tabelas }\end{array}$ \\
\hline & Canossa & 2009 & MP & PUC/SP & $\begin{array}{l}\text { Características didáticas de uma formação continuada para } \\
\text { professores do ensino médio, visando o trabalho com conceitos } \\
\text { de mediana e quartis }\end{array}$ \\
\hline & Giusti & 2012 & MA & ULBRA & $\begin{array}{l}\text { Ações e contribuições que uma formação continuada em } \\
\text { serviço envolvendo os conteúdos de Tratamento da Informação } \\
\text { pode oferecer para a prática pedagógica }\end{array}$ \\
\hline & Herebia & 2002 & MA & UCDB & $\begin{array}{l}\text { Características da formação inicial e continuada dos } \\
\text { professores que atuam na disciplina de Estatística }\end{array}$ \\
\hline & Lemos & 2011 & DO & $\mathrm{PUC} / \mathrm{SP}$ & $\begin{array}{l}\text { Investigação do desenvolvimento profissional de professores } \\
\text { que atuam no ensino fundamental sobre as medidas de } \\
\text { tendência central, em um contexto de formação continuada }\end{array}$ \\
\hline & Pamplona & 2009 & DO & UNICAMP & $\begin{array}{l}\text { Aprendizagem-ensino da Estatística na formação do Professor } \\
\text { de Matemática, ressaltando as práticas pedagógicas nela } \\
\text { envolvidas }\end{array}$ \\
\hline & Rodrigues & 2011 & DO & UFPR & $\begin{array}{l}\text { Conhecimentos necessários a compor uma proposta para o } \\
\text { ensino de noções de probabilidade na formação matemática } \\
\text { inicial de professores polivalentes }\end{array}$ \\
\hline & Rodrigues & 2005 & MA & UFPR & $\begin{array}{l}\text { Proposições e indicativos teóricos sobre a formação } \\
\text { matemática de professores e conhecimentos referentes a } \\
\text { noções de Probabilidade a ser ensinados numa disciplina de } \\
\text { Matemática para formação de professores de atuação } \\
\text { multidisciplinar }\end{array}$ \\
\hline \multicolumn{6}{|r|}{ Subtema: Prática Docente } \\
\hline \multirow{5}{*}{5} & Carneiro & 2003 & $\mathrm{DO}$ & $\mathrm{PUC} / \mathrm{SP}$ & $\begin{array}{l}\text { Compreensão de dinâmicas pedagógicas que possam aprimorar } \\
\text { o entendimento das representações estatísticas e experiências } \\
\text { pessoais de professores em torno dos conteúdos estatísticos }\end{array}$ \\
\hline & Alcântara & 2012 & MA & UFPE & $\begin{array}{l}\text { Como } 124 \text { educadores da área da Matemática trabalham os } \\
\text { conteúdos de Estatística }\end{array}$ \\
\hline & Gonçalves & 2005 & MA & UnB & $\begin{array}{l}\text { Construções e processos identificados na práxis de professoras } \\
\text { que ensinam Matemática no Ensino Fundamental em relação } \\
\text { ao ensino de noções estocásticas na escola }\end{array}$ \\
\hline & Pereira & 2007 & MP & $\mathrm{PUC} / \mathrm{SP}$ & $\begin{array}{l}\text { Como o professor do ensino médio ensina Estatística e como } \\
\text { ele passa a ensinar após passar por uma formação estatística }\end{array}$ \\
\hline & Silva & 2011 & MA & ULBRA & $\begin{array}{l}\text { Como está sendo desenvolvido o ensino de Estatística nas } \\
\text { escolas de Ensino Médio Integrado no Estado de Roraima }\end{array}$ \\
\hline \multicolumn{6}{|c|}{ Subtema: Conhecimento Profissional e Saberes Práticos } \\
\hline \multirow[t]{2}{*}{12} & Bigattão Jr. & 2007 & MP & $\mathrm{PUC} / \mathrm{SP}$ & $\begin{array}{l}\text { Como os docentes do ensino fundamental II veem os conceitos } \\
\text { estocásticos quando confrontados com situações-problema que } \\
\text { envolvam variabilidade }\end{array}$ \\
\hline & Cardoso & 2007 & MP & $\mathrm{PUC} / \mathrm{SP}$ & $\begin{array}{l}\text { Nível de mobilização dos conhecimentos por parte dos } \\
\text { professores do ensino médio que ensinam Estatística }\end{array}$ \\
\hline
\end{tabular}


DOI: http://dx.doi.org/10.20396/zet.v25il.8647576

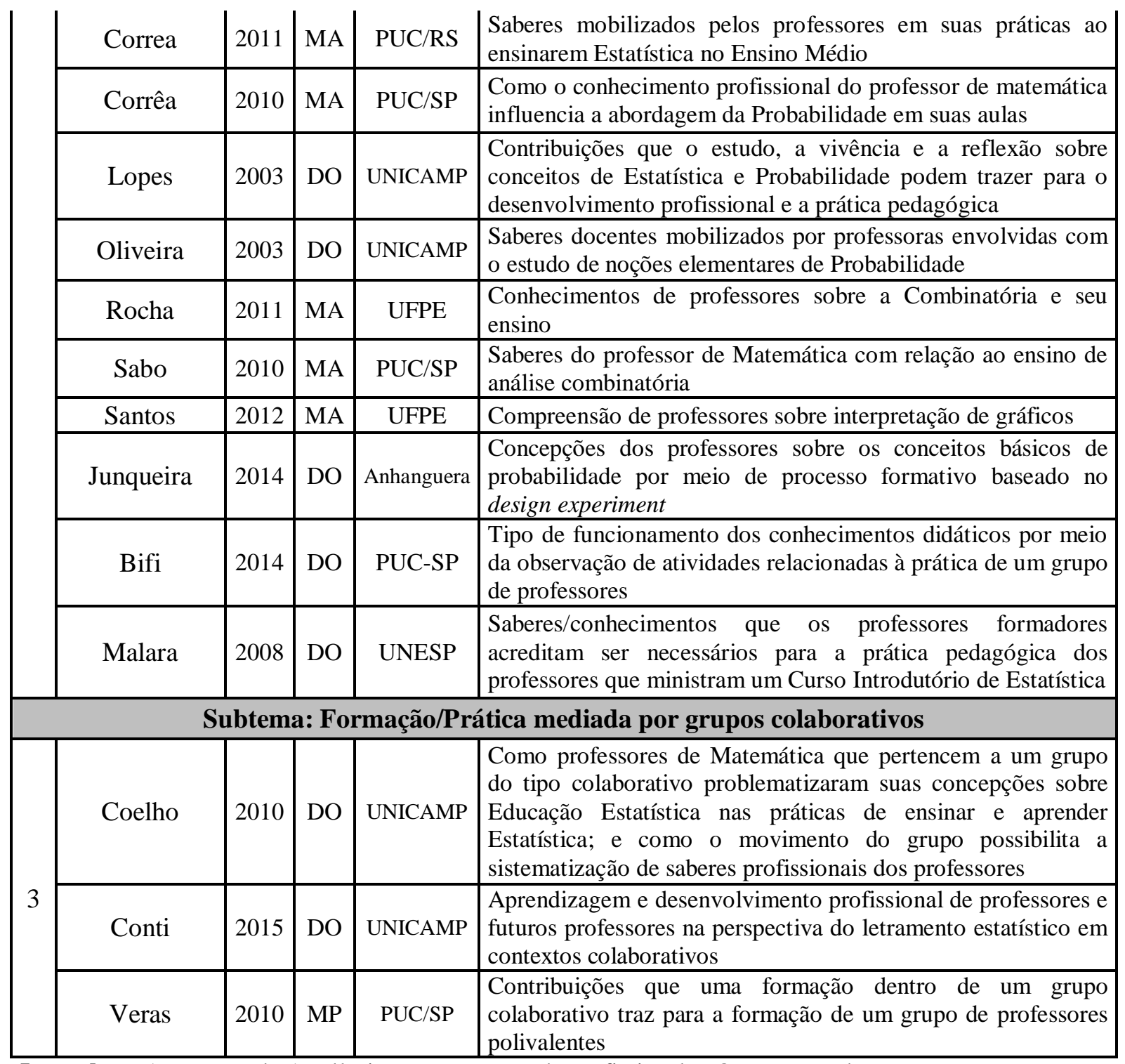

Legenda: MA = Mestrado Acadêmico; MP = Mestrado Profissional; DO = Doutorado.

\section{Formação inicial/continuada e desenvolvimento profissional}

Conquanto as expressões "formação" e "desenvolvimento" do professor sejam ocasionalmente tomadas como sinônimos, alguns estudos têm feito claras distinções (Ponte, 1998; Passos et al., 2006; Hargreaves, 1998). Passos et al. (2006), por exemplo, destacam que a Formação, em sua acepção tradicional, pressupõe "moldar" ou "dar forma" a algo ou alguém, segundo um modelo, que se supõe, seja o ideal (ou pelo menos desejável segundo a ótica de quem forma, ou seja, do formador). Esta noção apresenta-se muito associada à ideia de frequentar cursos - seja de graduação, no caso da formação dita inicial; ou de aperfeiçoamento/reciclagem, no caso da formação continuada -, de forma que neste contexto o formando assuma um papel mais passivo diante da própria ação formativa, já que, neste caso, o formador seria o agente ativo. 
Já o desenvolvimento profissional ocorre de formas múltiplas, que incluem cursos, mas também projetos, leituras, trocas de experiência, reflexões, atividades, enfim, traduz-se num processo dinâmico que engloba tanto a formação inicial como a permanente, onde são mobilizados não apenas os conhecimentos e os aspectos cognitivos, mas também as questões afetivas e de relacionamento (Passos et al., 2006). Na perspectiva do desenvolvimento profissional, portanto, o professor passa a ser sujeito de sua formação, e não mais um agente passivo do processo. Enquanto que na formação o movimento se dá de fora para dentro, com o professor assimilando conhecimentos e informações que lhe são transmitidas; no desenvolvimento profissional o movimento é de dentro para fora, "cabendo ao professor as decisões fundamentais relativamente às questões que quer considerar, aos projetos que quer empreender e ao modo como os quer executar" (Ponte, 1998, p. 30).

Dentro do subtema Formação inicial/continuada e desenvolvimento profissional, as principais ideias norteadoras das discussões trazidas pelas teses e dissertações giraram em torno das características e/ou contribuições de uma formação inicial/continuada para o trabalho com os conteúdos de Estatística, Probabilidade e Combinatória. Identificamos ainda duas abordagens que se destacam:

a) Estudos que discutiram proposições e indicativos teóricos sobre a formação inicial/continuada em geral de professores que ensinam Estatística, Probabilidade e Combinatória (Rodrigues, 2005; Rodrigues, 2011);

b) Estudos que desenvolveram atividades/oficinas/intervenções/entrevistas com vistas a produzir informações, avaliar e/ou descrever o processo de formação dentro de um contexto definido, seja na perspectiva inicial ou na continuada (Alves, 2012; Araújo, 2008; Canossa, 2009; Giusti, 2012; Herebia, 2002; Lemos, 2011; Pamplona, 2009).

Na maior parte dessas pesquisas, parece haver o consenso de que ainda há, no Brasil, uma formação inicial inadequada ou insuficiente para o trabalho com os conteúdos de Estatística, Probabilidade e Combinatória nos diversos níveis de ensino. Alguns problemas diagnosticados incluem:

- Alunos de Licenciatura em Matemática que trazem diversas lacunas e ideias equivocadas sobre Análise Combinatória, demonstrando, por exemplo, muitas dificuldades em problemas cujas soluções envolvem alocação e partição (Alves, 2012);

- Atitudes negativas manifestadas pelos professores frente aos conteúdos (Araújo, 2008; Lemos, 2011);

- A disciplina de Estatística é muitas das vezes ministrada por engenheiros, físicos, matemáticos ou outros profissionais sem formação específica no campo da Estatística (Herebia, 2002);

- Os professores com formação específica em Estatística sentem-se preteridos em relação aos demais profissionais, principalmente em virtude da carga horária reduzida. Muitas das vezes, a disciplina é tomada apenas para a complementação de 
carga horária do professor, o que impede a realização de um trabalho consistente (Herebia, 2002).

Dentre as propostas sugeridas para a formação inicial desses professores, estão: a abordagem das interpretações clássica e frequentista de Probabilidade, bem como o conhecimento das ferramentas matemáticas usadas nessas duas interpretações; a compreensão da probabilidade subjetiva em seu aspecto conceitual (em detrimento do aspecto procedimental); o conhecimento das justificativas e objetivos do ensino de Probabilidade nos anos iniciais de escolarização (Rodrigues, 2011); e a necessidade de desenvolvimento de um tipo de raciocínio não determinístico (Rodrigues, 2005).

Pamplona (2009), por sua vez, sugeriu o uso de diferentes abordagens para a aprendizagem-ensino dos conteúdos estatísticos, acompanhados da análise de uma questão do tipo: "Que fatores contribuíram para que essa determinada abordagem fosse empregada para ensinar esse conteúdo?". Isso se faria tanto como forma de favorecer a imaginação dos licenciandos a respeito da pertença na comunidade de prática dos professores que ensinam Estatística, quanto como forma de aumentar os seus saberes a respeito do uso dessas abordagens, levando-os a perceber que não existe uma única abordagem aplicável em todas as situações.

Algumas experiências desenvolvidas no contexto da formação inicial/continuada e do desenvolvimento profissional de professores, possibilitaram aos sujeitos das pesquisas a (re) construção e a ressignificação dos conhecimentos teóricos e práticos sobre o bloco de conteúdo de Tratamento da Informação (Giusti, 2012); a mudança de atitudes, concepções e da prática pedagógica (Araújo, 2008; Lemos, 2011); um avanço no nível de raciocínio e alfabetização estatística (Canossa, 2009); dentre outros.

Ainda no contexto da Formação inicial/continuada, pudemos observar que a ênfase das pesquisas está na perspectiva da formação continuada (Araújo, 2008; Canossa, 2009; Giusti, 2012; Lemos, 2011; Pamplona, 2009). A perspectiva da formação inicial esteve presente em três pesquisas (Rodrigues, 2005; 2011; Alves, 2012), além da dissertação de Herebia (2002), que tratou da perspectiva das formações inicial e continuada conjuntamente.

\section{Prática Docente}

Segundo Cochran-Smith e Lytle (1999), o termo "prática" tem sido comumente tomado no campo do ensino tanto para se referir ao fazer, desempenhar o trabalho da profissão, como para se justapor a teoria e pesquisa. No subtema Prática Docente, a ênfase trazida pelas pesquisas esteve em como se dá o ensino de Estatística, Probabilidade e Combinatória na prática de professores que trabalham com estes conteúdos, buscando identificar/descrever os diversos processos envolvidos nessa prática.

A pesquisa de Carneiro (2003), na busca de contribuir para a compreensão de dinâmicas pedagógicas que pudessem aprimorar o entendimento das representações estatísticas, concluiu pela viabilidade e eficácia de se promover um trabalho de reflexão em e 
sobre a ação docente em torno das representações gráficas estatísticas, admitindo o professor como corresponsável de todas as dinâmicas educativas propostas.

Alcântara (2012), ao avaliar como 124 educadores da área da Matemática trabalham os conteúdos de Estatística no ProJovem campo, em Pernambuco, concluiu que o ensino ocorre predominantemente a partir de coleta de dados em campo, com a posterior análise desses dados em sala de aula a partir da construção e interpretação de gráficos e tabelas. De acordo com a autora, o trabalho foi desenvolvido em articulação com a realidade social dos educandos, na perspectiva de integração de saberes, como preconizado pelo Programa do ProJovem.

Gonçalves (2005) discutiu o ensino de noções de Estocástica no Ensino Fundamental em Formosa-GO e concluiu que os professores apresentaram dificuldade em lidar com o jogo no ensino de Estatística; também concluiu que o currículo é percebido pelos professores como um elenco de conteúdos a serem ministrados, tratados de forma estanque e linear, em detrimento da perspectiva do currículo em rede, o que, segundo o autor, torna o ensino mecânico e descontextualizado. $\mathrm{O}$ autor ainda concluiu que muitas das professoras investigadas acabaram reduzindo o processo de ensino à transmissão/transferência de conhecimento, não se posicionando como mediadores do processo; além disso, as noções de acaso e aleatoriedade foram vistas como obstáculos epistemológicos enfrentados pelas professoras.

A pesquisa de Pereira (2007) desenvolveu um estudo de caso na busca de identificar, entre outras coisas, como um professor de Matemática do Ensino Médio ensina Estatística a seus alunos, e os principais resultados evidenciaram que o professor transmitia a seus alunos as suas próprias dificuldades, notadamente na análise interpretativa dos resultados; o grupo de alunos analisado foi classificado principalmente nos níveis técnico e mobilizável, segundo os níveis de conceitualização, de Aline Robert.

Investigando o ensino de Estatística nas escolas de Ensino Médio integrado no estado de Roraima, Silva (2011) obteve os seguintes resultados: a Estatística está presente nas escolas pesquisadas, sendo contemplada no currículo; todos os professores que ensinam este conteúdo são licenciados em Matemática e todos utilizam como principal metodologia a resolução de problemas.

Alguns problemas diagnosticados incluem a dificuldade verificada nos professores frente à compreensão de conceitos básicos de Estatística (Alcântara, 2012; Gonçalves, 2005; Pereira, 2007), a precariedade observada na formação dos professores em Educação Estatística (Silva, 2011; Pereira, 2007), a redução do processo de ensino ao uso do livro didático (Gonçalves, 2005; Silva, 2011), dentre outros.

Conhecimento profissional e saberes práticos

Para Tardif (2011), 
DOI: http://dx.doi.org/10.20396/zet.v25il.8647576

\begin{abstract}
a relação dos docentes com os saberes não se reduz a uma função de transmissão dos conhecimentos já constituídos. Sua prática integra diferentes saberes, com os quais o corpo docente mantém diferentes relações. Pode-se definir o saber docente como um saber plural, formado pelo amálgama, mais ou menos coerente, de saberes oriundos da formação profissional e de saberes disciplinares, curriculares e experienciais (Tardif, 2011, p. 36).
\end{abstract}

O subtema Conhecimento profissional e saberes práticos foi contemplado por 12 pesquisas, nas quais o foco girou em torno dos saberes e conhecimentos mobilizados na base da prática docente, sobretudo no trabalho com os conteúdos de Estatística, Probabilidade e Combinatória. A maior parte das pesquisas presentes neste subtema traz como eixo norteador de análise a compreensão/caracterização/diagnóstico desses saberes e conhecimentos, e as suas relações com a prática nos mais diversos contextos (Bigattão, Jr., 2007; Cardoso, 2007; Correa, 2011; Bifi, 2014; Oliveira, 2003; Rocha, 2011; Sabo, 2010; Santos, 2012; Junqueira, 2014; Malara, 2008). No caso das pesquisas de Lopes (2003) e Corrêa (2010), o foco de investigação incidiu sobre como esses conhecimentos e saberes influenciam e contribuem para o desenvolvimento profissional e/ou para a prática pedagógica dos professores.

As pesquisas diagnosticaram, dentre outros fatores, limitações, por parte dos professores pesquisados, no domínio dos conteúdos ensinados (Bigattão Jr., 2007; Cardoso, 2007; Corrêa, 2010; Rocha, 2011; Bifi, 2014; Sabo, 2010; Santos, 2012). Sabo (2010) e Rocha (2011) diagnosticaram a dificuldade demonstrada pelos professores em reconhecer se a ordem dos elementos é relevante ou não na formação de agrupamentos. Ambos ainda apontaram o princípio multiplicativo como estratégia positiva na resolução de problemas combinatórios pelos professores pesquisados. Junqueira (2014) verificou a fragilidade no planejamento e execução da ação docente, além da resistência ao uso de tecnologias.

Em outros casos, algumas dessas pesquisas identificaram e descreveram conhecimentos ou saberes específicos. Correa (2011) identificou dois saberes, distintos e complementares - os saberes das ciências da Educação e os saberes da ação pedagógica. Lopes (2003), por sua vez, identificou nas professoras analisadas os conhecimentos curricular e didático. Malara (2008) apontou evidências de diferentes tipos de saberes: derivados da experiência como aluno; derivados das concepções sobre a função do professor universitário; das concepções sobre aprendizagem; sobre como ensinar; relacionados com o conhecimento do conteúdo específico; relacionados à mobilização para o conhecimento; referentes à postura pessoal do professor-educador; relativos aos fatores que interferem na prática docente; e saberes relativos às dificuldades do aluno.

\title{
Formação/Prática mediada por grupos colaborativos
}

Grupos colaborativos são definidos por Parrilla (1996, apud Arnaiz et al., 1999) como aqueles em que todos os componentes compartilham as decisões tomadas e são responsáveis pela qualidade do que é produzido em conjunto, conforme suas possibilidades e interesses. No Subtema Formação/Prática mediada por grupos colaborativos, as pesquisas buscaram, em geral, avaliar as contribuições que um grupo colaborativo traz para a formação e a prática de grupos de professores, seja descrevendo como esses professores problematizam suas 
concepções sobre Educação Estatística nas práticas de ensinar e aprender Estatística (Coelho, 2010), ou investigando a compreensão de um grupo de professores polivalentes que ensinam Matemática em relação às atividades de Estatística (Veras, 2010), ou ainda, a partir da compreensão do desenvolvimento profissional de professores e futuros professores na perspectiva do letramento estatístico em contextos colaborativos (Conti, 2015).

Coelho (2010) mostrou que alguns saberes das professoras foram sistematizados e mobilizados pelas/nas interações dialógicas do grupo, tendo a contribuição do outro na produção e ressignificação do conhecimento, também destacando o debate e a contradição como "instigadores da produção de sentidos" (Coelho, 2010, p. 11). Para a autora, o fato de socializarem seus saberes levou as professoras a um sentimento de poder e de identificação profissional. A pesquisa ainda apontou a necessidade de uma reformulação no currículo da escola básica que ressalte a valorização da interpretação e da compreensão dos resultados estatísticos, e não apenas do cálculo matemático desprovido de sentidos.

Na pesquisa de Veras (2010), os resultados indicaram que o grupo colaborativo foi benéfico para a formação e desenvolvimento do grupo de sujeitos analisados, trazendo contribuições notadamente na aprendizagem de leitura e interpretação de gráficos e tabelas. A autora ressaltou, entretanto, que essas contribuições ainda foram insuficientes para que os professores adquirissem conhecimentos mais específicos sobre a construção dessas ferramentas estatísticas.

Conti (2015) destacou que o contexto colaborativo criado ao longo da investigação possibilitou evidenciar que os professores e futuros professores podem ser investigadores da própria prática e, com isso, se desenvolverem profissionalmente. A autora ainda descreve o contexto colaborativo como um bom alicerce para reflexões e ressignificações compartilhadas. Também ressalta a formação continuada como uma condição do trabalho do professor, na qual a sua prática pedagógica é tomada como ponto de partida, "valorizando sua formação e, em especial, a estatística; respeitando suas singularidades e potencialidades; possibilitando a ampliação dos conhecimentos e considerando suas necessidades num contexto colaborativo" (Conti, 2015, p. 7).

\section{Principais Aportes Teóricos e Abordagens Metodológicas}

As abordagens metodológicas adotadas privilegiaram, em geral, análises qualitativas, à exceção de Alves (2012), Herebia (2002), Pereira (2007), Silva (2011) e Bigattão Jr. (2007), que realizaram análises de natureza quali-quantitativa. Em Santos (2012), Cardoso (2007) e Canossa (2009) a natureza da abordagem metodológica não foi declarada pelos autores.

No que concerne o processo de coleta de dados, a modalidade de pesquisa que se destacou foi a pesquisa de campo (Giusti, 2012; Carneiro, 2003; Pereira, 2007; Corrêa, 2010; Lopes, 2003; Araújo, 2008; Gonçalves, 2005; Oliveira, 2003; Silva, 2011). Dentro deste contexto, Giusti (2012), Carneiro (2003), Pereira (2007), Corrêa (2010), Conti(2015), Lopes 
(2003) e Bifi (2014) realizaram estudos de caso; Araújo (2008) e Gonçalves (2005) adotaram a modalidade de pesquisa-ação; enquanto que Junqueira (2014) adotou a metodologia segundo o modelo Design Experiment, defendido por Paul Cobb e colaboradores.

Quanto aos objetivos das investigações, observamos pesquisas na modalidade analítico-descritiva (Herebia, 2002; Bigattão Jr., 2007) e na modalidade ensaio teórico (Rodrigues, 2005; Rodrigues, 2011). Correa (2011) declarou sua abordagem metodológica como analítica e compreensiva. Lemos (2011), Alcântara (2012), Rocha (2011), Sabo (2010), Malara (2008), Coelho (2010) e Veras (2010) classificam suas pesquisas apenas como qualitativas.

O principal instrumento utilizado para coleta de dados para análise foi a aplicação de questionários/entrevistas (Alves, 2012; Canossa, 2009; Giusti, 2012; Herebia, 2002; Alcântara, 2012; Bifi, 2014; Pereira, 2007; Silva, 2011; Bigattão Jr., 2007; Cardoso, 2007; Correa, 2011; Corrêa, 2010; Lopes, 2003; Oliveira, 2003; Rocha, 2011; Sabo, 2010; Santos, 2012; Conti, 2015; Malara, 2008; Veras, 2010). Em alguns casos também foi realizada uma análise documental e/ou bibliográfica (Alves, 2012; Giusti, 2012; Silva, 2011; Bigattão Jr., 2007; Rocha, 2011).

A narrativa biográfica, como instrumento da história oral, foi utilizada por Pamplona (2009) e Conti (2015) para coleta de dados. Os materiais escritos produzidos pelos professores sujeitos da pesquisa foram o meio de coleta de dados adotado por Lemos (2011). Coelho (2010) tomou como instrumento de produção de dados as filmagens das aulas dos professores. E, por fim, o diário de campo do pesquisador no contexto da observação participante foi utilizado por Gonçalves (2005) como instrumento de produção de dados.

Os sujeitos das pesquisas foram, em sua maioria, professores atuantes no ensino em diversos níveis, com exceção da dissertação de Pereira (2007), que tomou como sujeitos alunos e professores do Ensino Médio; e a de Alves (2012), que tomou como sujeitos alunos de um curso de licenciatura em Matemática.

Dentre os principais aportes teóricos tomados, destacamos os estudos sobre interpretação e níveis de compreensão gráfica de Curcio (Araújo, 2008; Santos, 2012; Veras, 2010), a Teoria dos Registros de Representação Semiótica, de Raymond Duval (Araújo, 2008; Carneiro, 2003), as ideias sobre letramento estatístico e os níveis de raciocínio estatístico, de Joan Garfield (Canossa, 2009; Bigattão Jr., 2007), a Teoria Antropológica do Didático e a Organização Praxeológica, de Yves Chevallard (Sabo, 2010; Veras, 2010) e as ideias de Carmen Batanero (Alves, 2012; Correa, 2010).

Destacamos também os aportes teóricos em: Dubois, com a Teoria do Modelo Combinatório Implícito (Alves, 2012); a Teoria Social de Aprendizagem, de Wenger (Pamplona, 2009); as ideias sobre a investigação como postura, de Cochram Smith e Lytle (Coelho, 2010); os níveis de funcionamento do conhecimento, de Aline Robert (Pereira, 2007); e a perspectiva teórica do professor reflexivo, de Paulo Freire (Lopes, 2003). 
Apontamos ainda alguns aportes teóricos em: Nóvoa (Giusti, 2012; Lemos, 2012), Perrenoud (Giusti, 2012), Shulman (Giusti, 2012; Lemos, 2011), Thiollent e Barbié (Gonçalves, 2005), Shamos (Cardoso, 2007), Gauthier (Corrêa, 2011), Fischbein (Oliveira, 2003), Gal, Batanero, Hargreaves, Fiorentini, Watson (Conti, 2015) e Bakhtin (Coelho, 2010).

\section{Algumas Conclusões e Considerações Finais}

Ao longo deste artigo, foram apresentados e discutidos os principais focos de análise presentes em teses e dissertações produzidas em programas brasileiros de pós-graduação na temática da formação/prática de professores que ensinam os conteúdos de Estatística, Probabilidade e Combinatória. Também foram exploradas as principais abordagens metodológicas e aportes teóricos da pesquisa, assim como um breve balanço dos principais resultados obtidos.

A análise das 29 teses e dissertações nos permitiu diagnosticar a ênfase dada ao subtema Conhecimento profissional e saberes práticos (12 pesquisas), no qual o foco principal esteve na compreensão/caracterização/diagnóstico desses saberes e conhecimentos bem como suas relações com a prática nos mais diversos contextos.

No subtema Formação inicial/continuada e desenvolvimento profissional, as principais abordagens incluíram proposições e indicativos teóricos sobre a formação inicial/continuada em geral de professores que ensinam Estatística, Probabilidade e Combinatória; além de estudos que desenvolveram atividades/oficinas/intervenções/ entrevistas com vistas a produzir informações, avaliar e/ou descrever o processo de formação dentro de um contexto definido. Os principais resultados convergem para o fato de que ainda há, no Brasil, uma precariedade observada na formação dos professores em Educação Estatística.

No subtema Prática Docente, as teses e dissertações analisadas trouxeram como principal foco de análise identificar/descrever o processo de ensino, enfatizando como este ensino se manifesta na prática de professores que trabalham com os conteúdos de Estatística, Probabilidade e Combinatória. Alguns problemas diagnosticados incluíram a redução do processo de ensino à transmissão/transferência de conhecimento, quase sempre restrito ao uso do livro didático; a percepção do currículo pelos professores como um elenco de conteúdos a serem ministrados, tratados de forma estanque e linear, tornando o ensino mecânico e descontextualizado; outro problema destacado foi a dificuldade verificada nos professores frente à compreensão de conceitos básicos de Estatística, agregado ao fato de que os professores transmitem a seus alunos essas mesmas dificuldades.

No Subtema Formação/Prática mediada por grupos colaborativos, as discussões giraram em torno das contribuições e potencialidades que um grupo colaborativo traz para a formação e a prática de professores. Os principais resultados evidenciaram efeitos benéficos para a formação e desenvolvimento dos grupos de sujeitos analisados, notabilizando o 
contexto de trabalho colaborativo como um ambiente rico em aprendizado, troca de experiências e compartilhamento/produção de conhecimento, servindo de importante alicerce para reflexões e ressignificações na formação e na prática dos indivíduos participantes.

As principais abordagens metodológicas adotadas privilegiaram, em geral, análises qualitativas, notadamente na modalidade de pesquisa de campo, onde se destacou a realização de estudos de caso, visando, em geral, a busca de detalhamentos e análises de sistemas e contextos delimitados, tanto na busca de produzir informações sobre eles, como, em última instância, modifica-los.

$\mathrm{Na}$ descrição dos principais aportes teóricos adotados pelas pesquisas, ganham destaque os estudos sobre interpretação e níveis de compreensão gráfica de Curcio, a Teoria dos Registros de Representação Semiótica de Raymond Duval, as ideias sobre letramento estatístico e os níveis de raciocínio estatístico de Joan Garfield, a Teoria Antropológica do Didático, a Organização Praxeológica, de Yves Chevallard e as ideias de Carmen Batanero.

Em última análise, destacamos a grande diversidade de abordagens metodológicas e focos de investigação; além da ênfase dada pelas pesquisas às questões relacionadas ao ensino de Estatística, conteúdo mais privilegiado pelas investigações. Outro destaque esteve na convergência observada nas teses e dissertações analisadas no que diz respeito à necessidade de se criarem mecanismos de aprimoramento na formação inicial de professores para o trabalho com os conteúdos de Estatística, Probabilidade e Combinatória, ponto que parece ser central na análise dos problemas relativos ao ensino desses conteúdos.

\section{Referências}

Arnaiz, P., Herrero, A. \& De Haro, R. (1999). Trabajo colaborativo entre profesores y atención a la diversidad. Comunidad Educativa, 262, 29-35.

Cochran-Smith, M. \& Lytle, S. L. (1999). Relationships of Knowledge and Practice: teacher learning in communities. In: Review of Research in Education. 24, 249-305.

Hargreaves, A. (1998). Os professores em tempo de mudança: O trabalho e a cultura dos professores na idade Pós-Moderna. Lisboa: MacGraw-Hill.

Passos, C. L. B., Nacarato, A. M., Fiorentini, D., Miskulin, R. G. S., Grando, R. C., Gama, R. P., Megid, M. A. B. A., Freitas, M. T. M. \& Melo, M. V. (2006). Desenvolvimento profissional do professor que ensina Matemática: uma meta-análise de estudos brasileiros. Quadrante, 15 (1 e 2), 193-219.

Ponte, J. P. (1998). Da formação ao desenvolvimento profissional. Anais do Encontro Nacional de Professores de Matemática PROFMAT (pp. 27-44). Lisboa: APM.

Santos, R. M. (2015). Estado da arte e história da pesquisa em Educação Estatística em programas brasileiros de pós-graduação. Tese de Doutorado em Educação. Campinas: Universidade estadual de Campinas.

Tardif, M. (2011). Saberes docentes e formação profissional. Petrópolis: Vozes. 


\section{APÊNDICE 1: Relação das teses e dissertações do corpus de análise deste estudo}

Alcântara, L. R. (2012). O ensino de conteúdos estatísticos no projovem campo - saberes da terra em Pernambuco. Dissertação de Mestrado em Educação Matemática e Tecnológica. Recife: Universidade Federal de Pernambuco.

Alves, R. C. (2012) O ensino da análise combinatória na educação básica e a formação de professores. 2012. 176 f. Dissertação de Mestrado em ensino de Matemática. Rio de Janeiro: Universidade Federal do Rio de Janeiro.

Araujo, E. G. (2008). O Tratamento da Informação nas séries iniciais: uma proposta de formação de professores para o ensino de gráficos e tabelas. Dissertação de Mestrado em Educação Científica e Tecnológica. Florianópolis: Universidade Federal de Santa Catarina.

Bifi, C. R. (2014) Conhecimentos estatísticos no ciclo I do ensino Fundamental: um estudo diagnóstico com professores em exercício. Tese de Doutorado em Educação Matemática. São Paulo: Pontifícia Universidade Católica de São Paulo.

Bigattão JR., P. A. (2007) Concepção do Professor de Matemática sobre o Ensino da Estocástica. 2007. Dissertação de Mestrado profissional em ensino de Matemática. São Paulo: Pontifícia Universidade Católica de São Paulo.

Canossa, R. (2009) O professor de matemática e o trabalho com medidas separatrizes. Dissertação de Mestrado profissional em ensino de Matemática. São Paulo: Pontifícia Universidade Católica de São Paulo.

Cardoso, R. (2007) O professor de matemática e a análise exploratória de dados no ensino médio. Dissertação de Mestrado profissional em ensino de Matemática. São Paulo: Pontifícia Universidade Católica de São Paulo.

Carneiro, C. C. C. (2003) Estatística nas Séries Iniciais do Ensino Fundamental: Buscando Caminhos. Tese de Doutorado em Educação Matemática. São Paulo: Pontifícia Universidade Católica de São Paulo.

Coelho, M. A. V. (2010). Os saberes profissionais dos professores: a problematização das práticas pedagógicas em estatística mediadas pelas práticas colaborativas. Tese de Doutorado em Educação. Campinas: Universidade Estadual de Campinas.

Conti, K. C. (2015) Desenvolvimento profissional de professores em contextos colaborativos em práticas de letramento estatístico. Tese de Doutorado em Educação. Campinas: Universidade estadual de Campinas.

Correa, A. A. (2011) Saberes docentes e educação estatística: um estudo das práticas docentes no ensino médio. Dissertação de Mestrado em Educação em Ciências e Matemática. Porto Alegre: Pontifícia Universidade Católica do Rio Grande do Sul.

Corrêa, M. W. (2010) O conhecimento profissional e a abordagem do ensino da probabilidade: um estudo de caso. Dissertação de Mestrado em Educação Matemática. São Paulo: Pontifícia Universidade Católica de São Paulo.

Giusti, N. M. R. (2012). Formação continuada dos professores dos anos iniciais: uma experiência sobre o conteúdo de tratamento da informação. Dissertação de Mestrado 
DOI: http://dx.doi.org/10.20396/zet.v25il.8647576

em ensino de Ciências e Matemática. Canoas: Universidade Luterana do Brasil, Canoas.

Gonçalves, H. J. L. (2005). A educação estatística no ensino fundamental: discussões sobre a práxis de professoras que ensinam matemática no interior de Goiás. Dissertação de Mestrado em Educação. Brasília: Universidade de Brasília.

Herebia, R. B. (2002). A característica da formação inicial e continuada docente de estatística da UCDB. Dissertação de Mestrado em Educação). Campo Grande: Universidade Católica Dom Bosco.

Junqueira, A. L. N. (2014). Probabilidade na Educação Básica: um estudo sobre concepções de professores de Matemática. Tese de Doutorado em Educação Matemática. São Paulo: Universidade Anhanguera.

Lemos, M. P. F. (2011). O desenvolvimento profissional de professores do $1^{o}$ ao $5^{\circ}$ ano do ensino fundamental em um processo de formação para o ensino e a aprendizagem das medidas de tendência central. Tese de Doutorado em Educação Matemática. São Paulo: Pontifícia Universidade Católica de São Paulo.

Lopes, C. A. E. (2003). O Conhecimento Profissional dos Professores e suas Relações com Estatística e Probabilidade na Educação Infantil. Tese de Doutorado em Educação. Campinas: Universidade Estadual de Campinas.

Malara, M. B. S. (2008). Os Saberes Docentes Do Professor Universitário Do Curso Introdutório de Estatística Expressos no Discurso dos Formadores. Rio Claro: Universidade Estadual Paulista.

Oliveira, P. C. (2003). O Processo de Aprender noções de Probabilidade e suas Relações no Cotidiano das Séries Iniciais do Ensino Fundamental: uma história de parceria. Doutorado em Educação. Campinas: Universidade Estadual de Campinas.

Pamplona, A. S. (2009). A formação estatística e pedagógica do professor de matemática em comunidades de pratica. Tese de Doutorado em Educação. Campinas: Universidade Estadual de Campinas.

Pereira, S. A. (2007). Um estudo a respeito do professor de Matemática e a implementação de uma sequência didática para a abordagem da Estatística no Ensino Médio. Dissertação de Mestrado profissional em ensino de Matemática. São Paulo: Pontifícia Universidade Católica de São Paulo.

Rocha, C. A. (2011). A formação docente e o ensino de problemas combinatórios: diversos olhares, diferentes conhecimentos. Dissertação de Mestrado em Educação Matemática e Tecnológica. Recife: Universidade Federal de Pernambuco.

Rodrigues, J. M. S. (2011). A probabilidade como componente curricular na formação matemática inicial de professores polivalentes. Tese de Doutorado em Educação. Curitiba: Universidade Federal do Paraná.

Rodrigues, J. M. S. (2005). Formação matemática de professores de atuação multidisciplinar nas séries iniciais do ensino fundamental: indicativos com vista a estudos de noções de probabilidade. Dissertação de Mestrado em Educação. Curitiba: Universidade Federal do Paraná. 
DOI: http://dx.doi.org/10.20396/zet.v25il.8647576

Sabo, R. D. (2010). Saberes docentes: a análise combinatória no ensino médio. Dissertação de Mestrado em Educação Matemática. São Paulo: Pontifícia Universidade Católica de São Paulo.

Santos, K. B. C. (2012). Explorando a compreensão de gráficos nos anos iniciais do ensino fundamental: um estudo com professores do $4^{\circ}$ e $5^{\circ}$ ano dos municípios de Igaraçu e Itapissuma. Dissertação de Mestrado em Educação Matemática e Tecnológica. Recife: Universidade Federal de Pernambuco.

Silva, A. M. (2011). O ensino de estatística nas escolas de ensino médio integrado no estado de Roraima. Dissertação de Mestrado em ensino de Ciências e Matemática. Canoas: Universidade Luterana do Brasil.

Veras, C. M. (2010). A estatística nas séries iniciais: uma experiência de formação com um grupo colaborativo com professores polivalentes. Dissertação de Mestrado profissional em ensino de Matemática. São Paulo: Pontifícia Universidade Católica de São Paulo. 